\title{
Notes on the young of the "Hokke," Pleurogrammus azonus Jordan et Metz ${ }^{*}$
}

\author{
Tokiharu ABE \\ TOKAIKU SUISAN KENKYUJO \\ (Formerly Central Fisheries Station of Japan) \\ and \\ Zoological Iustitute, Faculty of Science, \\ Tokyo University
}

In former years, when the spring herring approacned the south-western coast of Hokkaido to spawn or, when the sardine abounded the Japanese seas, the "Hokke", Pleurogrammus azonus JORDAN et METZ, was of minor economic importance, and little attention was paid to its fishery and biology. It was only seven years ago (May, 1943) that the resources studies of this species were started at the Hokkaido Fisheries Experiment Station possibly stimulated by the unusual demand for fish at that time, which coupled with a reported increase in abundance of this fish resulted in a catch from Hokkaido of 44181 metric tons for 1943, 61376 metric tons for 1944, 73617 metric tons for 1945, 80141 metric tons for 1946 , 61325 metric tons for 1947 and 60368 metric tons for 1948.* Since April, 1947, the resources studies were also made at the Central Fisheries Station of Japan (formerly translated as Imperial Fisheries Experiment Station) on the "Hokke" of the Japanese coasts of Japan Sea and coasts of Hokkaido parallel with the studies carried out at the Hokkaido Fisheries Experiment Station on the fish from the coasts of Hokkaido. In April, 1950, however, due to the drastic change in the research system at the Fisheries Agency, Ministry of Agriculture and Forestry, the resources studies of the "Hokke" was designated as one of the main items of researches exclusively of the new Hokkaidoku Suisan Kenkyujo, and it seems desirable that the present writer would leave the more detaild study of the "Hokke"

*昭租 25 年 7 月 26 日受理

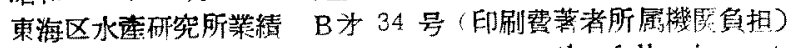

*** After the present paper went to press, the following catch records of the "Hokke" from Hokkaido appeared in the reports by Hokkaido Suisanbutsu Kensajo:

47847 metric tons (from Hokkaido alone) in 1949 .

$55494 \quad, \quad$ ( ) in 1950. 
in the hands of the staff members of this station. In this paper he wishes to present some notes on the young of the "Hokke", of which, so far as he is aware, but a few records have hith rto been published. It is his pleasing duty to express here his thanks to Dr. M. TAUCHI (former Director of the Central Fisheries Station of Japan), Dr. M. UDA (Director of the Tokai-ku Suisan Kenkyujo), Mr. T. KAWANA (of the same Station), Mr. J. NAKAI (of the same Station), Mr. Y. TAKEMURA (of the same Station), Mr. K. TAMURA (Kumaishi, Hokkaido), Mr. Y. SUGINO (Kudo, Hokkaido), Mr. Y. OGAWA (Nihonkai-ku Suisan Kenkyujo), and many other Japanese colleagues and fishermen for their kindness.

\section{Published records and informations relevant to the young}

In $1936 \mathrm{Mr}$. A. G. KAGANOVSKY reported the occurrences of the young of Pleurogrammus azonus (JORDAN et METZ) ("Morskoi Lenock" or "Terpuuk" in Russian) near the surface of the sea of southern Primorskaya. According to him, the young of 85-95 mm (possibly total) length were taken by a purse sein near Askold I. (Peter the Great Bay) on July 23, 1931, and those of 120-140 mm (possibly total) length* were taken in large quantities by herring set nets in the southern part of Primorskaya during 2-27, July, 1935. These records stand in line with the informations heard by the present writer from Mr. K. TAMURA and Mr. Y. OKUNO who have been in Sakhalin for more than twenty years and with those from Mr. J. NAKAI who made frequent voyages across Japan Sea while he was a staff member of the Fisheries Experiment Station of Korea prior to the end of the recent war. According to the two former, the young of some $60 \mathrm{~mm}$ total length appeared near the eastern coast of Aniva Bay late in May, those of 100$120 \mathrm{~mm}$ total length were taken there in abundance $(18800-22600 \mathrm{~kg}$ per net) by herring set nets during the middle of June-middle of July, and those of some 180 $\mathrm{mm}$ total length were caught during August-September. The blue of the back disapeared, they added, when the young attained the total length of some $120-180$ mm. Mr. Nakai told several times that he saw the young of the "Hokke" often in the offshore of Japan Sea, and recently he has presented to the writer for study the specimens of them which will be described later. The smallest "Hokke" recorded from the Japanese waters seems to be of ca. $150 \mathrm{~mm}$ total length seen in July (Mr. Y. HIRANO's pamphlet of 1946, p. 18, and his paper appeared in the "Journal of the Hokkaido Fisheries Scientific Institution**, iv, no. 1, p. 18, 1947).

\footnotetext{
* Identified by the late Mr. A. J. TARANETZ.

** "Hokkaido Suisan Shikenjo" has been translated in various ways: eg. "Hokkaido Fisheries Experiment Station", "Hokkaido Fisheries Scientific Institution", etc.
} 
On the other hand, Mr. HIRANO made artificial fertilization of the "Hokke" eggs (1946), and figured with Mr. H. KONDO (1948 a larva of $11 \mathrm{~mm}$ total length. The specimens presented by Mr. NAKAI bridge over the gap between the developmental stage represented by this figure and that represented by a specimen of $165 \mathrm{~mm}$ total length (A. No. 7964) obtained by the present writer on July 5, 1948, from among many young herrings of $170-250 \mathrm{~mm}$ total length from Urakawa, southern Hokkaido, at the Central Wholesale Market of Tokyo.

On November 25, 1933, Mr. KAGANOVSKY also found one example of Pleurogrammus azonus of ca. $220 \mathrm{~mm}$ (probably total) length among the fishes taken by drift nets for sardine, at a station 80 miles south of Askold I., where the depth was more than 2,000 meters. As regards the migration of the young "Hokke", the details are as yet to be worked out.*

\section{Description of the examples of the young}

Leaving the presentation of the results of the variation studies on the adult "Hokke" for a future -work (which is indispensable for identifying the young), the specimens of the young "Hokke" mentioned above will be described below. Like the young of Hexagrammos otakii JORDAN et STARKS and Agrammus agrammus (TEMMINCK et SCHLEGEL), they are characterized by the blue color of the body which might be interpreted as adapted to the life near the surface during the young stages**.

A. No. 7964: Bears the data mentioned above. The measurements are expressed in hundredths of the standard length, $146 \mathrm{~mm}$. Except for the slender body, bluish tint of the back and silvery white color of the lower part of sides (as in Scomber japonicus HOUTTUYN), it is similar to the adult (although the belly is damaged and the courses of the lateral lines of this part of the body can not be seen). Length of head 21; greatest depth of body $\mathrm{ca} .17$; greatest width of body $c a$. 10 ; least depth of caudal peduncle 5 ; length of snout (measured parallel to the longitudinal axis of body) 6 ; diameter of eye 4 .

D. XXII 29 (anteriormost spines increasing in length backwards); A. I 27; P.

*The result of the study on the migration of the adut "Hokke" will be reported upon in full detail in the near future.

**vide Prof. K. UCHIDA's papers of 1929 (p. 373) and 1930 (p. 86, p. fig. 1), the late Mr. S. NAKAMURA's paper of 1936 (p. 138, figs. 79 and 80) and Drs. Y. OSHIMA and N. NAKAMURA's paper of 1944 (p. 94). As regards the young of the other Japanese members of the Hexagrammidae, there seems to be no published record. 
left. ca. 22, right. damaged; V. damaged; C. xvili (owermest 4 rays segmented)/ $6+8 / c a$. xiv or more (uppermost 5 rays segmented).

T. No. 1689: (Fig. 1, a, b.): Total length $63 \mathrm{~mm}$. Presented by Mr. J. NAKAI. Col'ected by "Senchu-maru" (scientific vessel of Fisheries Exferiment Station of Akita-ken), at $39^{\circ} 35^{\prime} 00^{\prime \prime} \mathrm{N}, 135^{\circ} 45^{\prime} 31^{\prime \prime} \mathrm{E}$ (near "Yamato-tai"), at 1:00-1: $10 \mathrm{a}$. m., March' 20, 1950, by a large-mouthed larva-net, at the velocity of 2 miles per hour. The surface temperature was $7^{\circ} \mathrm{C}$. The collerting was made for the study of the saedine larvae und $\mathrm{I}$ the direction of Mr. NAKAI. Neasurements are expressed in hundredths of the standard length, $55 \mathrm{~mm}$ : measured to the posterior margin of the two vertically placed pale spots at the base of caudal fin). Length of head 22; greatest depth of body 15 ; greatest width of head 10 , that of trunk 9 ; least depth of caudal peduncle 7 ; length of snout (measured parallel to the longitudinal axis of body) 5 ; diameter of eye $c h .6$.

D. XX 30 (anteriormost spines increasing in 'engih bacliwarcs); $\dot{A} .28$ (possibly I 27): P. left. ca.24, right. 23; V. left. damager, right. I 5 ; C. xix (lowermost 4 rays segmented) $/ 6+8 / \mathrm{xx}$ (uppermost 4 rays segmented).

The uppermost, second, fourth and fifth lateral lines are discernible anteriorly (the third is lacking).

Dorsal parts of head and trunk greenish blue, upper, part of side dark, pale below. A pair of dark spots behind interorbital space, and two vertically placed dark triangular spots on the proximal part of caudal fin on each side, which are preceded by the two vertically placed pale spots at the base of caudal fin. A pale longitudinal band on each side near the base of dorsal fin. Eight very small black dots on the mid-ventral line, between anal and caudal, followed by another at the lower part of the base of caudal.

T. No. 1687 (Fig. 2, a, b): Bears the same date as T. No. 1689. Total length $45 \mathrm{~mm}$. Measurements are expressed in hundredths of the standard length, 39.3 $\mathrm{mm}$ (measured to the posterior margin of the two vertically placed pale spots at the base of caudal fin). Length of head 22; greatest depth of body 15 ; greatest width of head 10 , that of trunk 7 (trunk compressed); least depth of caudal peduncle 7; jenglh of snout (measured parallel to the longitudinal axis of body) 4 ; diameter of eye 8.

D. 51 (anteriormost rass, possibly spines, increasing in length backwards); $A$. 28; P. left. 24, right. ca. 24 ; V. left. 6 (tip damaged), right damaged; C. xvii (lowermost 3 rays segmented) $/ 7+8 / \mathrm{xx}$ (uppermost ca: 4 rays segmented).

Only the "2rd" lateral line from above is seen indistinctly. 

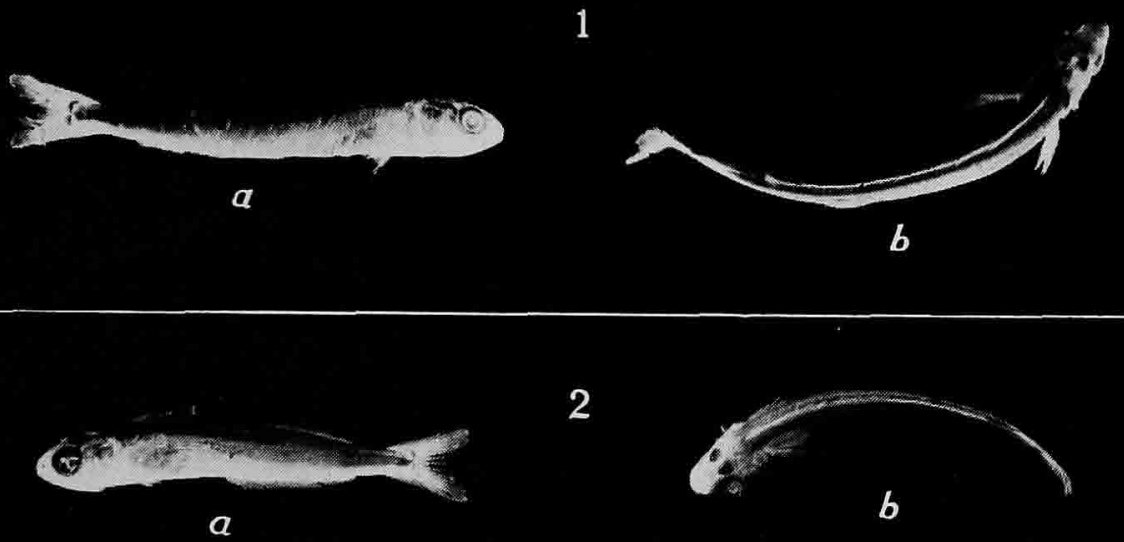

2
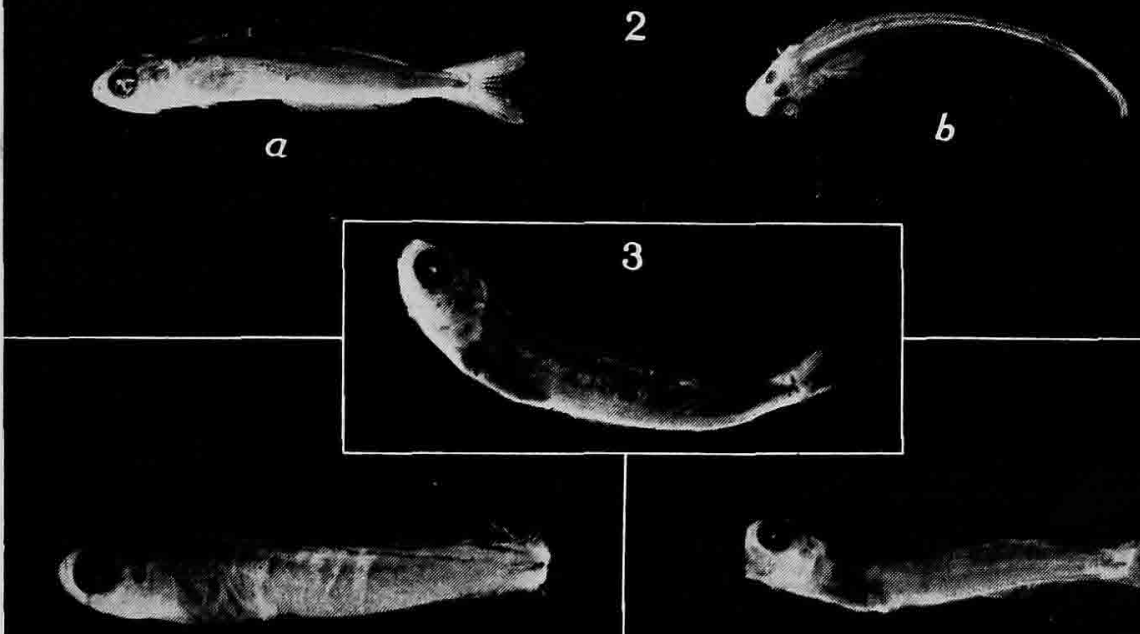

3 
Except for the presence of the much darker longitudinal line at the base of dorsal fin on each side and two (instead of one) minute black dots on the ventral part of the base of caudal fin, the coloration is as in the specimen described just above.

The following three specimens are fragile, demaged in part, and bear the same data as the two specimens (T. Nos. 1689 and 1687) just described to which they bear general resemblance. It is highly probable thgt they are the young of the "Hokke," and it seems advisable to report upon these specimens provisionally here.

T. No. 1684 (Fig. 3). Standard length ca. $26.7 \mathrm{~mm}$. D. ca. 49 ; A. ca. 28 ; P. left. ca. 23 , right. ca. 23 . V. very small, rays can not be counted; C. ca. xi/6+8 (segmented, mostly not branched)/ca. xiii.

Coloration as in T. No. 1687. The longitudinal black line at the base of dorsal fin on each side of body is very conspicous. Lateral lines are not discernible.

I. No. 1683 (Fig. 4). Standard length ca. $21.3 \mathrm{~mm}$. D. damaged (rays distinct ; A. ca. 28 ; P. damaged (rays developed); V. very small (rays developed, but can not be counted); C. damaged (rays developed .

The skin at thc base of dorsal fin is damaged. Lateral lines are not discernible.

T. No. 1682 (Fig. 5). Standard length ca. $18.0 \mathrm{~mm}$. The dorsal and anal fin-rays are not fully developed (only the rudiments appearing proximally), the fins being continuous membranes through the caudal fin which has fin-rays fairly well differentiated already; the lower pectoral fin-rays are not well developed, some 16 rays are visible in the upper $3 / 4$ of the fin. Ventral fins and lateral lines are not discernible.

The black longitudinal line along the base of dorsal fin on each side of body is vert. thin but distinct.

\section{REFERENCES}

BELCHOUK, L. A. 1938. Contribution on age determination of Pleurogrammus azonus. Bull. Pacific Sci. Inst. Fish. Ocean, xiv, pp. 165-168. (In Russian.)

HIRANO, Y. and TAKAHASHI, T. 1943. Some obsevations on the "Hokke". Hokkaido Suisan Shikenjo Junpo, no. 577 (Sept. 5, 1943), pp. 8-10. (In Japanese.)

HIRANO, Y. 1946. On the "Hekke" (Pleurogrammus azonus JORDAN et METZ) from Hokkaido. 34 pp. (In Japanese.)

1947. On the "Hokke" from Hokkaido. Journal of the Hokkaido

Fisheries Scientific Institution, iv, no. 1, pp. 10-22. (In Japanese.)

HIRANO, Y. and KONDO, H. 1948. On the development of Atka mackerel eggs.

Joural of the Hokkaido Fisheries Scientific Insttution, v, no 3, pp. 1-3. (In Japanese.)

HUBBS, C. L. 1943. Terminology of early stages of fishes. Copeia, 1943, p. 260. 
KAGANOWSKY, A. G. On the occurrence of (Pleurogrammus azonus) near the surface in southern Primorskaya. Bull. Far Eastern Branch. Acad. Sci. U.S.S.R., xviii, pp. 170-171. (In Russian.)

NAKAMURA, S. 1936. Young stages of the littoral fishes appearing near Ko- minato. XIX. Yōshoku Kaishi, vi, nos. 7, 8, pp. 138-138. (In Japanese.)

OSHIMA, Y. and NAKAMURA, N. On the life-history of Hexagrammos otakii - JORDAN et STARKS. Suisan Gakkaiho, ix, nos. 2-4, pp. 81-89. (In Japanese.) UCHIDA, K. 1929. Various larval adaptations of fishes. Zool. Mag. (Tokyo), xli, pp. 373--374. (In Japanese.)

1930. Pisces, Cyclostomata and Cephalochordata. In "Seibutsugaku" by Iwanami Shoten; 118 pp., 1 pl. (In Japánese.)

YAMAMOTO, G. and NISHIOKA, C. 1948. Breeding habits and developmental processes of greenling, Hexagrammos otakii JORDAN et STARKS. Seibutu, iii, no, 5, pp. $167-170$. (In Japanese.)

\section{EXPLANATION OF PLATE}

Fig. 1. Young "Hokke" of $63 \mathrm{~mm}$ total length (T. No. 1689):-
Fig. 2.
$45 \mathrm{~mm}$
(T. No. 1687).

Fig. 3. Probably the young of "Hokke", standard length ca. $26.7 \mathrm{~mm}$ (T. No. 1684).

Fig. 4. ca. $21.3 \mathrm{~mm}$ (T. No. 1683).

Fig. 5.

,"

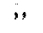
ca. $18.0 \mathrm{~mm}$ (T. No. 1682).

\section{ADDITION}

After this paper went to press, the following report was published:

KAMBARA, H. 1950. Investigation of Atka mackerel. I. On the young of Atka mackerel appearing along the Pacific coasts of Hokkaido. Hokkaido Fisheries Scientific Institution, vii, no. 11, pp. 19-27. (In Japanese.) 